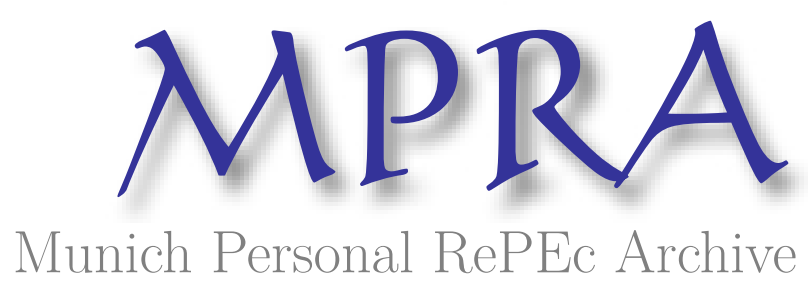

\title{
Unit root behavior in energy futures prices
}

Serletis, Apostolos

1992

Online at https://mpra.ub.uni-muenchen.de/1744/

MPRA Paper No. 1744, posted 11 Feb 2007 UTC 


\section{UNIT ROOT BEHAVIOR IN ENERGY FUTURES PRICES[*]}

This paper re-examines the empirical evidence for random walk type behavior in energy futures prices. In doing so, tests for unit roots in the univariate time-series representation of the daily crude oil, heating oil, and unleaded gasoline series are performed using recent state-of-the-art methodology. The results show that the unit root hypothesis can be rejected if allowance is made for the possibility of a one-time break in the intercept and the slope of the trend function at an unknown point in time.

\section{INTRODUCTION}

Recently the efficient markets hypothesis and the notions connected with it have provided the basis for a great deal of research in financial economics. A voluminous literature has developed supporting this hypothesis. Briefly stated, the hypothesis claims that asset prices are rationally related to economic realities and always incorporate all the information available to the market. This implies that price changes should be serially random, and hence the absence of exploitable excess profit opportunities.

Despite the widespread allegiance to the notion of market efficiency, a number of studies have suggested that certain asset prices are not rationally related to economic realities. For example, Summers (1986) argues that market valuations differ substantially and persistently from rational valuations and that existing evidence (based on common techniques) does not establish that financial markets are efficient.

Market efficiency requires that price changes are uncorrelated and implies a unit root in the level of the price or logarithm of the price series. This is consistent with the empirical work of Nelson and Plosser (1982) who argue that most macroeconomic time series have a unit root (a stochastic trend). Nelson and Plosser described this property as one of being "difference stationary" (DS) so that the first difference of a time series is stationary. An alterative "trend stationary" (TS) model, where a stationary component is added to a deterministic trend term, has generally been found to be less appropriate.

Perron (1989), however, challenged this view and argued that most macroeconomic time series (and in particular those used by Nelson and Plosser) are TS if one allows for structural changes in the trend function. In particular, Perron's argument is that only certain "big shocks" have had permanent effects on the various macroeconomic time series and that these shocks were exogenous -- that is, not a realization of the underlying data generation mechanism of the various series. Modelling such shocks as exogenous removes the influence of these shocks from the noise function and, in general, leads to a rejection of the null hypothesis of a unit root.

Given the serious implications of unit roots for both empirical and theoretical work as well as the stakes in this line of research, this paper examines the empirical evidence for random walk type behavior in energy futures prices. The remainder of the paper consists of three sections. The first section briefly describes the data. The second section considers alternative tests of the unit root null hypothesis and presents the results. The final section summarizes the paper. 


\section{DATA}

To examine the empirical evidence for random walk type behavior in energy futures prices, I use daily observations from the New York Mercantile Exchange (NYMEX) on spot-month futures prices for crude oil, heating oil and unleaded gasoline. The sample period is $83 / 07 / 01$ to $90 / 07 / 03$ for all commodities except unleaded gasoline, which begins in 85/03/14. Figures 1 to 3 graph the (logarithm of the) price series.

\section{EMPIRICAL EVIDENCE}

\section{Autocorrelation Based Tests}

Since market efficiency requires serial independence of returns, serial correlation coefficients of orders one to ten have been computed for each contract series and are presented in Table 1. Panel A of Table 1 contains autocorrelations of the log contract prices. These autocorrelations suggest that $(\log )$ contract prices are highly autocorrelated. In particular, the first-order autocorrelations are greater than .993 for every series and the smallest of the autocorrelation coefficients is .920 .

Panel B of Table 1 reports results in the same fashion as panel A, except that now the first differences of the log contract prices (which measure contract returns) are being considered. Clearly, contract returns are not autocorrelated, suggesting that the hypothesis of (weak form) efficiency cannot be rejected -- that is, the past history of returns offers no opportunities for extraordinary profits.

\section{Univariate Tests for Unit Roots}

It was argued earlier that market efficiency implies a unit root in the level of the price or logarithm of the price series. Here, using Phillips's and Perron's (1988) procedure, I test whether the univariate processes of the (natural) logarithms of spot-month energy futures prices contain unit roots. This is a general approach and exploits recent developments in functional central limit theory in order to obtain nonparametric corrections for infinite-dimensional nuisance parameters. The basic idea is to estimate one of two non-augmented Dickey-Fuller regressions defined from

Multiple line equation(s) cannot be represented in ASCII text.

where $\mathrm{T}$ denotes the sample size.

Given equation (1), the null hypotheses of a unit root, with or without a drift, i.e. $\mathrm{H}[1][\mathrm{o}]: \mathrm{a}^{*}=1$ and $\mathrm{H}[2][\mathrm{o}]:=0,=1$, are tested against the stationary alternatives by means of the adjusted $\mathrm{t}$ - and F-statistics $\mathrm{Z}\left(\mathrm{t}\left[{ }^{*}\right]\right)$ and $\mathrm{Z}([1])$. In equation (2), which allows for a deterministic trend, the null hypotheses $\mathrm{H}[3][\mathrm{o}]=1, \mathrm{H}[4][\mathrm{o}]:=0=1$, and $\mathrm{H}[5][\mathrm{o}]=0, \mathrm{~B}=0=1$ can be tested by means of the test statistics $\mathrm{Z}(\mathrm{t} \mathrm{Z}()$, and $\mathrm{Z}([2])$, respectively. The formulae for the $\mathrm{Z}$ statistics are not presented here. They are derived in Perron (1990) and discussed and applied in Perron (1988).

The results of applying the $Z$ statistics are presented in Table 2. The simple unit root test of the t-statistic type, $Z(t \sim *)$, as well as the $Z([1])$ statistic, are insignificant (at the $1 \%$ level) for all the series. The inclusion of a time trend as in (2) and the use of the 
$\mathrm{Z}(\mathrm{t} \mathrm{Z}([3])$, and $\mathrm{Z}([2])$ statistics do not change the qualitative results. The overall conclusion is that the evidence is (reasonably) supportive of the unit root hypothesis.

Perron (1989), however, argues that most macroeconomic time series (and in particular those used by Nelson and Plosser, 1982) are trend stationary if one allows for a one-time change in the intercept or in the slope (or both) of

the trend function. The postulate is that certain shocks (such as, in the present case, the November 1985 regime shift in OPEC pricing policy as well as the precipitous decline of crude oil prices from $\$ 31$ per barrel to the $\$ 9$ level, beginning in late 1985) do not represent a realization of the underlying datagenerating mechanism of the series under consideration and that the null should be tested against the trendstationary alternative by allowing, under both the null and alternative hypotheses, for the presence of a one-time break (at a known point in time) in the intercept or in the slope (or both) of the trend function.

Perron's (1989) assumption that the break point is uncorrelated with the data has been criticized, most notably by Christiano (1988) who argues that problems associated with "pre-testing" are applicable to Perron's methodology and that the structural break should instead be treated as being correlated with the data. More recently, Zivot and Andrews (1990), in the spirit of Christiano (1988), treat the selection of the break point as the outcome of an estimation procedure and transform Perron's (1989) conditional (on structural change at a known point in time) unit root test into an unconditional unit root test.

Following Zivot and Andrews (1990), I test the null hypothesis of an integrated process with drift against the alternative hypothesis of trend stationarity with a onetime break in the intercept and slope of the trend function at an unknown point in time, using the following augmented regression equation (see Zivot and Andrews for more details):

Multiple line equation(s) cannot be represented in ASCII text.

In equation (3), testing the null hypothesis of a unit root amounts to choosing the break fraction X -- the ratio of pre-break sample size to total sample size -- in order to minimize the one-sided t-statistic for testing $=1$. In particular, I reject the null hypothesis of a unit root if (.) <t(.) where (.) denotes the "estimated break point" critical value reported in Zivot and Andrews.

Table 3 presents the results using regression (3) with $X$ chosen so as to minimize the one-sided t-statistic for testing $=1$ over all $\mathrm{T}-2$ regressions (where $\mathrm{T}$ is the number of observations). For each tentative choice of X, I chose the truncation lag parameter, $\mathrm{k}$, to be correlated with the data. In particular, working backwards from $\mathrm{k}=15$, I chose $\mathrm{k}$ such that the t-statistic on the last included lag in the autoregression was greater than 1.6 in absolute value and that the t-statistic on the last lag in higher order autoregressions was less than 1.6. The t-statistics on the parameters for the following respective hypotheses are also presented (in parentheses): $\mathrm{mu}=0,0=0$, Beta $=0,=$ 0 , and $=1$. 
To evaluate the significance of the asymptotic "estimated break point" critical values reported in Zivot and Andrews (1990, Table 4A) are used. Clearly, the null hypothesis of a unit root can be rejected at the $5 \%$ significance level. Also, the estimated coefficients on the constant (mu), the post-break constant dummy (Theta), and the post-break slope dummy $(\mathrm{mu})$ are highly significant. These results imply that the failure of the Phillips-Perron Z statistics to reject the null hypothesis that energy futures prices have a unit root reflects not the presence of the unit root, but instead that the data are trend-stationary about a broken trend.

\section{CONCLUSIONS}

This paper tests for unit roots in the univariate time-series representation of the daily crude oil, heating oil, and unleaded gasoline spotmonth futures prices. The results show that the random walk hypothesis for daily energy futures prices can be rejected if allowance is made for the possibility of a one-time break in the intercept and the slope of the trend function at an unknown point in time.

The rejection of the random walk model does not necessarily imply that energy futures markets are inefficient or that energy futures prices are not rational assessments of fundamental values. However, the results highlight the important role that certain big trend breaks could play in tests for unit roots and raise the important question of whether such trend breaks should be treated like any other, or differently, before we classify energy futures prices as either TS or DS.

In addition to its economic importance, the issue of whether energy futures prices are TS or DS has implications for both estimation and hypothesis testing, both of which rely on asymptotic distribution theory. It has been recognized, for example, that inappropriate de-trending of integrated process produces spurious variation in the detrended series at low frequencies, while inappropriate differencing of trending processes produces spurious variation in the differenced series at high frequencies.

*The author is indebted to a referee for detailed constructive suggestions.

**Department of Economies, University of Calgary, 2500 University Drive N.W., Calgary, Alberta, Canada, T2N 1N4.

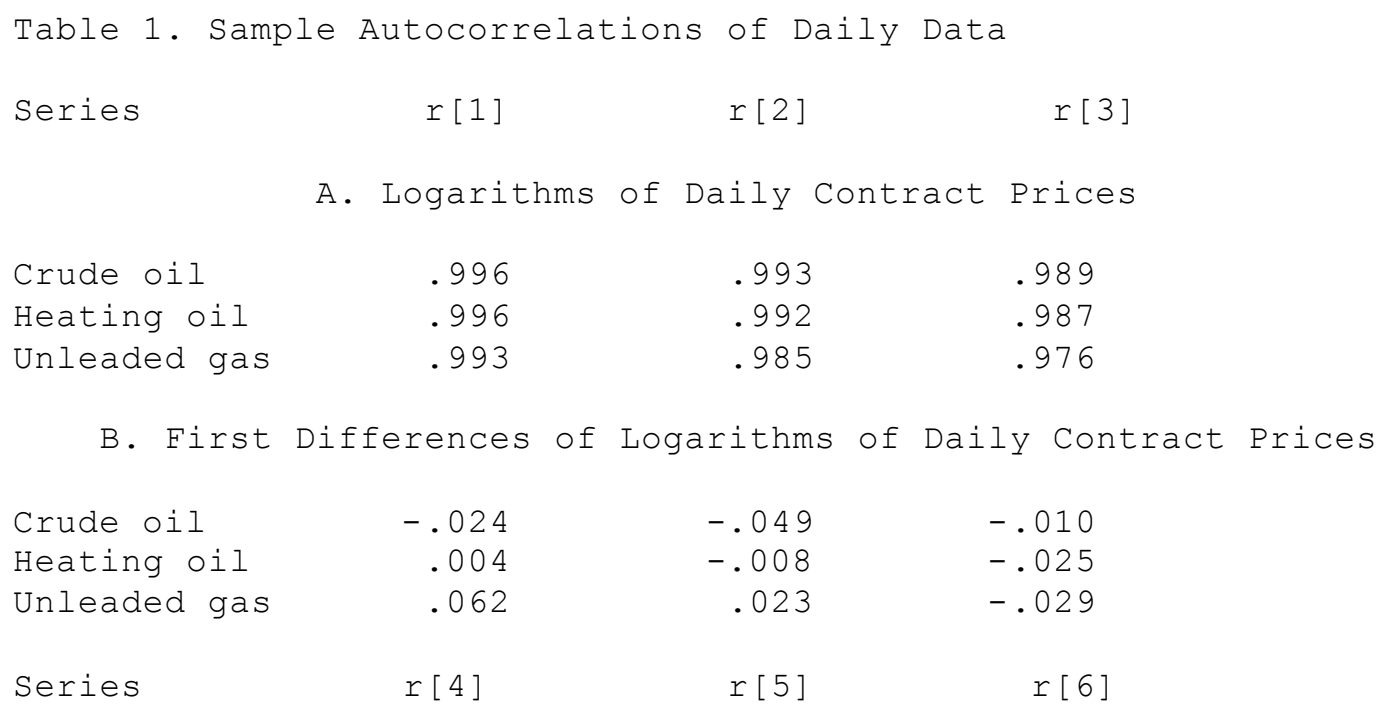


A. Logarithms of Daily Contract Prices

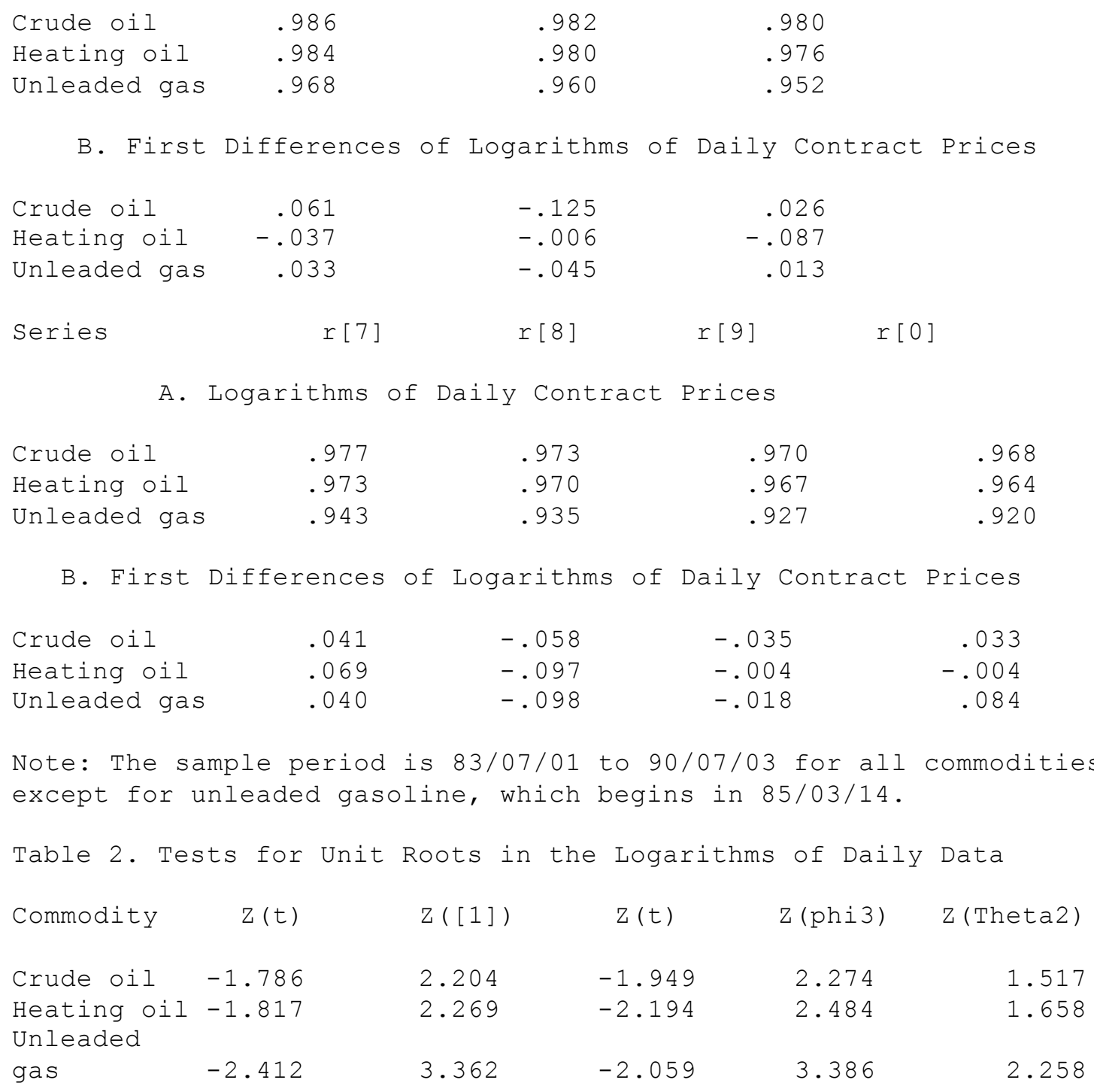

Note: i) Significant at the $[* *] 1 \%,[*] 5 \%$, and $+10 \%$

level. See Fuller (1976, Table 8.5.2) and Dickey

and Fuller (1981, Table IV) for the critical values.

Table 3. Tests for a Unit Root Using Zivot and Andrews' Procedure Multiple line equation(s) cannot be represented in ASCII text.

\begin{tabular}{|c|c|c|c|c|c|}
\hline Series & $\mathrm{T}$ & $\mathrm{T}[\mathrm{b}]$ & $\mathrm{k}$ & Theta & \\
\hline Crude oil & 1604 & 626 & 12 & $\begin{array}{c}.087 \\
(5.0)\end{array}$ & $\begin{array}{l}-.016 \\
(-4.5)\end{array}$ \\
\hline Heating oil & 1587 & 616 & 12 & $\begin{array}{l}-.005 \\
(-2.7)\end{array}$ & $\begin{array}{l}-.017 \\
(-4.9)\end{array}$ \\
\hline Unleaded gas & 1225 & 211 & 11 & $\begin{array}{l}-.004 \\
(-1.2)\end{array}$ & $\begin{array}{l}-.014 \\
(-3.1)\end{array}$ \\
\hline
\end{tabular}

Series

$\begin{array}{ccccc}\text { Crude oil } & -.000 & .000 & .974[*] & .022 \\ \text { Heating oil } & -.000 & .000 & .07 .6) & (-5.1) \\ & & .072\left[{ }^{*}\right] & .022\end{array}$




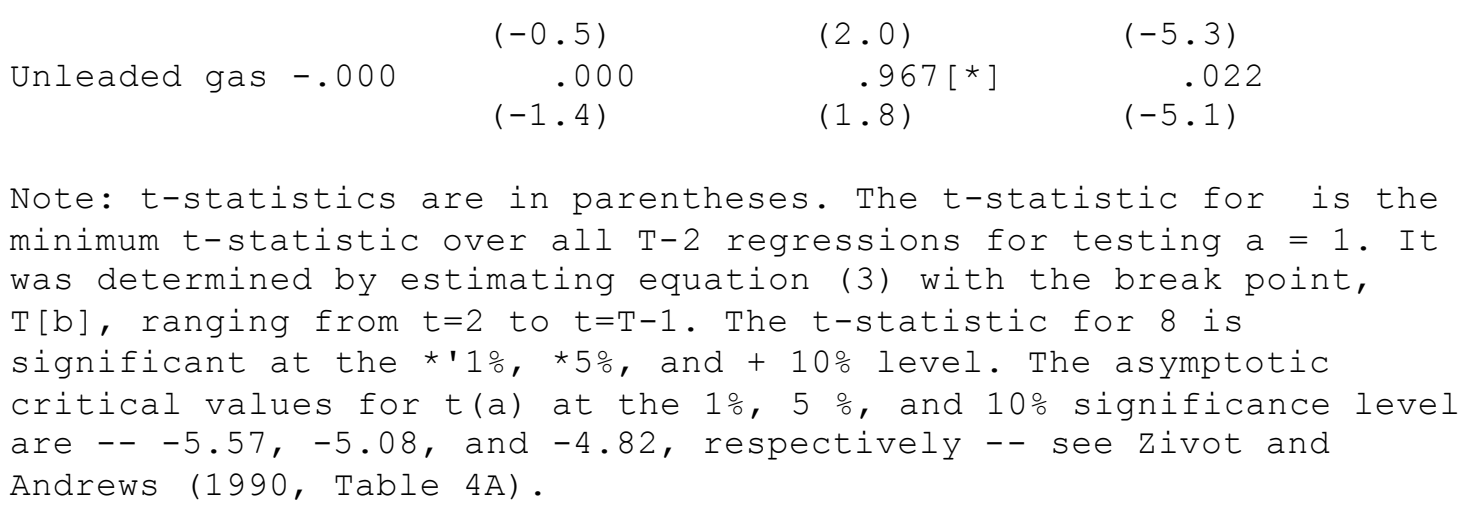

GRAPH: Figure 1. Crude Oil Daily 1-Month Log Futures Prices: 01/07/83 -03/07/90

GRAPH: Figure 2. Heating Oil Daily 1-Month Log Futures Prices: 01/07/83-03/07/90 0.2

GRAPH: Figure 3. Unleaded Gas, Daily 1-Month Log Futures Prices: 14/03/8503/07/90

\section{REFERENCES}

Christiano, Lawrence J. "Searching for a Break in GNP. " National Bureau of Economic Research Working Paper 2695.

Dickey, David A. and Wayne A. Fuller. "Likelihood Ratio Statistics for AutoregressiveTime Series with a Unit Root." Econometrica 49 (1981) 1057-72.

Fuller, Wayne A. Introduction to Statistical Time Series. New York: John Wiley and Sons (1976).

Hsieh, D.A. "The Statistical properties of Daily Foreign Exchange Rates: 1974-1983." Journal of International Economics 24 (1988) 129-145.

Nelson, Charles R. and Charles I. Plosser. "Trends and Random Walks in Macroeconomic Time Series: Some Evidence and Implications. "Journal of Monetary Economics 10 (1982) 139-162.

Perron, Pierre. "Trends and Random Walks in Macroeconomic Time Series: Further Evidence From a New Approach." Journal of Economic Dynamics and Control 12 (I 988) 297-332.

Perron, Pierre. 'The Great Crash, the Oil Price Shock, and the Unit Root Hypothesis." Econometrica 57 (1989) 1361-1401.

Perron, Pierre. 'Tests of Joint Hypotheses in Time Series Regression With a Unit Root," in Advances in Econometrics: Co-Integregation, Spurious Regression and Unit Roots, Vol. 8, G.F. and T.B. Fomby (eds.), JAI Press, 1990.

Phillips, Peter C.B. and Pierre Perron. 'Testing for a Unit Root in Time Series Regression." Biometrica 75 (1988) 335-46. 
Summers, Laurence H. "Does the Stock Market Rationally Reflect Fundamental Values." Journal of Finance 41 (1986) 591-601.

Zivot, E. and D.W.K. Andrews. "Further Evidence on the Great Crash, the Oil Price Shock, and the Unit Root Hypothesis." Cowles Foundation discussion Paper No. 944 (1990) Yale University. 